\title{
A comparative study on efficacy and safety of glycopyrronium bromide +salmeterol/fluticasone and tiotropium bromide+salmeterol/fluticasone in chronic obstructive pulmonary disease
}

\author{
Kumar D. ${ }^{1}$, Khare A. ${ }^{2 *}$, Babu Raman R. ${ }^{3}$, Srivastava R. ${ }^{4}$, Ghosh D. ${ }^{5}$ \\ DOI: https://doi.org/10.17511/ijmrr.2019.i02.12
}

${ }^{1}$ Deepak Kumar, Tutor, Department of Pharmacology, Hind Institute of Medical Sciences, Barabanki, Uttar Pradesh, India.

${ }^{2 *}$ A.K. Khare, Associate Professor, Department of Pharmacology, Hind Institute of Medical Sciences, Barabanki, Uttar Pradesh, India.

3 Ram Babu Raman, Tutor, Department of Pharmacology, Hind Institute of Medical Sciences, Barabanki, Uttar Pradesh, India.

${ }^{4}$ Rahul Srivastava, Assistant Professor, Department of Chest and T.B., Hind Institute of Medical Sciences, Barabanki, Uttar Pradesh, India.

5 Dibyadeb Ghosh, Professor, Department of Pharmacology, Hind Institute of Medical Sciences, Barabanki, Uttar Pradesh, India.

Objective: To compare the effect of tiotropium bromide and glycopyrronium bromide in the treatment of chronic obstructive pulmonary disease. Methods: This was an open labeled Randomized controlled trial study. Patients diagnosed with COPD according to the Global Initiative for chronic Obstructive Lung Disease (GOLD) strategy were included in the study. The patients were divided in two groups and each group had 100 patients. Group A- COPD patients on Tiotropium bromide + Salmeterol/Fluticasone; Group B - COPD patient on Glycopyrronium bromide + Salmeterol/Fluticasone. Tiotropium bromide: $18 \mathrm{mcg} O D$, Glycopyrronium bromide: $50 \mathrm{mcg}$ OD along with Salmeterol $50 \mathrm{mcg} /$ Fluticasone $100 \mathrm{mcg}$ was given. Results: The mean age of patients of Group A and Group B was 56.28 \pm 7.78 and $57.64 \pm 8.06$ years respectively. Baseline variables were comparable between the groups. There was significant $(p<0.05)$ difference in PFT parameters between the groups at 12 and 24 weeks except for FEV1/FVC. The mean change was higher in Group B compared to Group A from 0 week to 24 weeks. There was clinical improvement among all the patients in both the groups. Conclusion: Once-daily GLY demonstrated similar effects to TIO when combined with SAL/FP in patients with moderate and severe COPD.

Keywords: Chronic obstructive pulmonary, Tiotropium bromide, Glycopyrronium bromide, Fluticasone, Salmeterol

Corresponding Author

A.K. Khare, Associate Professor, Department of Pharmacology, Hind Institute of Medical Sciences, Barabanki, Uttar Pradesh, India.

Email: akharester@gmail.com
How to Cite this Article

To Browse

Kumar D, Khare AK, Raman RB, Srivastava R, Ghosh D. A comparative study on efficacy and safety of glycopyrronium bromide +salmeterol/fluticasone and tiotropium bromide+salmeterol/fluticasone in chronic obstructive pulmonary disease. Int J Med Res Rev. 2019;7(2):122-129. Available From https://ijmrr.medresearch.in/index.php/ijmrr/article/

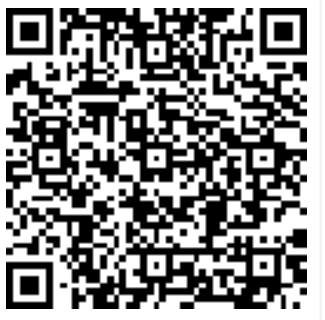
view/1045

Manuscript Received 2019-04-10

Conflict of Interest No
Review Round 1 2019-04-20

Funding $\mathrm{Nil}$
Review Round 2 2019-04-25

Ethical Approval Yes
Review Round 3

Accepted 2019-04-30

Plagiarism X-checker $6 \%$

Note

(C) 2019 by Deepak Kumar, A.K. Khare, Ram Babu Raman, Rahul Srivastava, Dibyadeb Ghosh and Published by Siddharth Health Research and Social Welfare Society. This is an Open Access article licensed under a Creative Commons Attribution 4.0 International License https://creativecommons.org/licenses/by/4.0/ unported [CC BY 4.0] 


\section{Introduction}

Chronic obstructive pulmonary disease (COPD) is a prevalent disease caused by chronic airway and pulmonary inflammation, primarily as a result of persistent inhalation of toxic particles and gases in tobacco smoke [1]. The inflammatory process results in tissue repair, remodeling of the airways and lung parenchyma, and eventually loss of terminal and respiratory bronchioles followed by emphysematous destruction of the alveoli. Clinically this manifests as progressive airflow obstruction that is not fully reversible [2].

Several distinct long-acting muscarinic antagonists (LAMAs) with different characteristics and dosing schedules are approved for maintenance therapy of COPD, and a number are in clinical development. Tiotropium bromide (Spiriva $\AA^{8}$ Boehringer Ingelheim, Ingelheim, Germany) was the first oncedaily LAMA approved for maintenance treatment in COPD and is extensively used in the management of COPD. In July 2012, aclidinium bromide (Ekila ${ }^{8}$, Almirall, Barcelona, Spain), a novel twice-daily LAMA, was approved in Europe and the USA, and more recently, in April 2014, umeclidinium bromide (Incruse ${ }^{\circledR}$ Ellipta ${ }^{\circledR}$, Glaxo Smith Kline, London, UK) was approved in Europe and the USA.

The dry powder formulation of glycopyrronium bromide was developed for inhalation as a treatment for COPD under the compound code NVA237 (Seebri®, Novartis, Basel, Switzerland) and is delivered through the low-resistance Breezhaler® device [3]. Glycopyrronium was approved in late 2012 as a once-daily maintenance treatment in adults with COPD and was the first once-daily alternative to tiotropium.

Glycopyrronium acts as a highly potent, competitive muscarinic receptor antagonist that binds to muscarinic receptors in bronchial smooth muscle and inhibits acetylcholine-mediated bronchoconstriction. Glycopy-rronium binds with high affinity to M1-3 receptors.

It exhibits higher selectivity (4-5-fold) for $\mathrm{M}_{1}$ and M3 subtypes over $M_{2}$, and shows faster dissociation from $M_{2}$ than from $M_{1}$ and $M_{3}$ Tiotropium shares similar characteristics, including a higher selectivity for $M_{3}$ receptors than for $M_{2}$ receptors, and tiotropium and aclidinium also dissociate more slowly from the M3 receptor than from the M2 receptor.
There are some subtle differences when compared with tiotropium, shown in in vitro comparisons during the drug development process. Glycopyrronium exhibits greater binding selectivity for $M$ over $M 2$ receptors than tiotropium, and has higher kinetic selectivity and faster dissociation from M2 receptors than from M3 receptors when compared with tiotropium [4].

The long acting $\beta 2$ agonist (LABA) salmeterol is an alternative inhaled bronchodilator therapy and is often prescribed in a combination inhaler with the anti-inflammatory corticosteroid fluticasone propionate (FP). This combination of salmeterol and FP (SFC) has demonstrated a broad range of antiinflammatory effects that are greater than those seen with inhaled corticosteroid (ICS) monotherapy and the likely explanation for this is a molecular interaction (synergy) between the LABA and ICS $[5,6]$.

The present study was conducted to compare the effect of tiotropium bromide and glycopyrronium bromide in the treatment of chronic obstructive pulmonary disease.

\section{Methods}

Patients and Methods: This was an open labeled Randomized controlled trial conducted in the Department of Pharmacology and Pulmonary Medicine at Hind Institute of Medical Sciences, Safedabad, Barabanki. Patients of either sex in age group of 18-65 years, diagnosed with COPD according to the Global Initiative for chronic Obstructive Lung Disease (GOLD) strategy were included in the study. Participation was voluntary and no allowances were paid to patients.

Exclusion criteria: Patients suffering from other associated chronic diseases (T2DM, hypertension, liver disease, and renal disease), allergy to anticholinergic drugs, recent eye surgery (e.g. cataract) within two months, women of child bearing age (30$45 \mathrm{yr}$.) and patients undergoing major surgery within three months were excluded from the study.

Ethics: The study was approved by the Ethics Committee of the Institute and informed consent was taken from each participant before enrolling in the study. Patients were free to drop out of the study at any time.

The patients were divided in two groups and each group had 100 patients. 
Group A- COPD patients on Tiotropium bromide + Salmeterol/Fluticasone; Group B-COPD patient on Glycopyrronium bromide + Salmeterol/Fluticasone.

Drug administration- The drugs were given to the patients on the basis of physician's discretion depending upon the LFT report.

Tiotropium bromide: $18 \mathrm{mcg} O D$

Glycopyrronium bromide: 50 mcg OD

Along with Salmeterol $50 \mathrm{mcg} /$ Fluticasone $100 \mathrm{mcg}$

A detailed history and clinical examination were done for each case. Specific emphasis was given on the treatment as well as life style modifications of the patients as instructed by the doctor.

The following test was done at 0,12 and 24 weeks: 01. Pulmonary Function Test (PFT)

\section{Complete Blood Count}

\section{X-ray Chest-PA view}

In order to see effect of bronchodilator response spirometry was performed 15-30 minutes after administering a short acting beta-agonist like salbutamol or terbutaline. The PFT of the patients was recorded on $0,12 \& 24$ weeks. The patients were then reviewed after a period of 12 weeks. The PFT of all the patients were recorded again after 12 and 24 weeks.

Statistical analysis: The results are presented in frequencies, percentages and means. The Chisquare test was used to compare categorical variables between the groups. Students Unpaired and Paired $t$-test was used to continuous variables between the groups. The $p<0.05$ was considered significant. All the analysis was carried out on SSPS 16.0 version for Windows (Chicago, Inc., USA).

Surgical interventions: No patient was subjected to any interventional procedure or surgery. LFT was done after giving a proper demonstration.

\section{Results}

The mean age of patients of Group A and Group B was $56.28 \pm 7.78$ and $57.64 \pm 8.06$ years respectively. Majority of patients of both Group A (68\%) and Group B (70\%) were males. More than half of patients of both Group A (59\%) and Group B (60\%) were smoker. There was no significant $(p>0.05)$ difference in the basic characteristics of patients between the groups showing comparability of the groups in terms of basic characteristics (Table-1).
Table-1: Distribution of basic characteristics of patients between the groups.

\begin{tabular}{|c|c|c|c|}
\hline Groups & $\begin{array}{l}\text { Group A } \\
(n=100)\end{array}$ & $\begin{array}{l}\text { Group B } \\
(n=100)\end{array}$ & p-value1 \\
\hline Age in years, mean \pm sd & $56.28 \pm 7.78$ & $57.64 \pm 8.06$ & 0.22 \\
\hline \multicolumn{4}{|l|}{ Gender, no. (\%) } \\
\hline Male & $68(68.0)$ & $70(70.0)$ & \\
\hline Female & $32(32.0)$ & $30(30.0)$ & 0.76 \\
\hline \multicolumn{4}{|l|}{ Smoking habit, no. (\%) } \\
\hline Present & $59(59.0)$ & $60(60.0)$ & \\
\hline Absent & $41(41.0)$ & $40(40.0)$ & 0.88 \\
\hline Height in $\mathrm{cms}$, mean $\pm \mathrm{sd}$ & $158.22 \pm 8.35$ & $157.72 \pm 11.18$ & 0.72 \\
\hline Weight in kgs, mean \pm sd & $55.02 \pm 10.80$ & $54.52 \pm 9.97$ & 0.73 \\
\hline $\begin{array}{l}\text { BMI in } \mathrm{kg} / \mathrm{mtrs} 2, \\
\text { mean } \pm \text { sd }\end{array}$ & $22.14 \pm 4.89$ & $22.29 \pm 5.90$ & 0.85 \\
\hline \multicolumn{4}{|c|}{ Severity of disease, no. (\%) } \\
\hline Moderate & $78(78.0)$ & $78(78.0)$ & 1.00 \\
\hline Severe & $22(22.0)$ & $22(22.0)$ & \\
\hline
\end{tabular}

1Unpaired t-test/Chi-square test

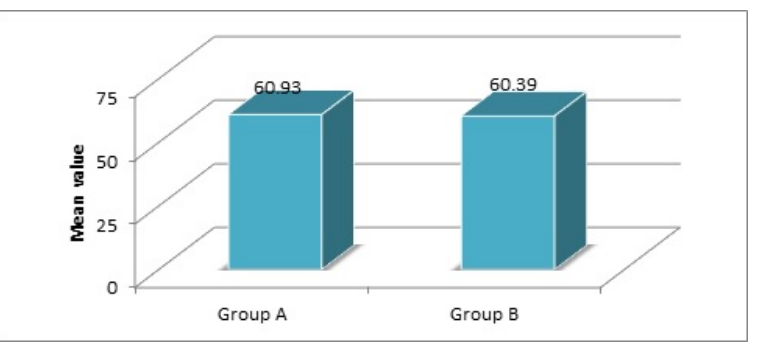

Fig.-1: Comparison of predicted FEV1 between the groups

There was no significant ( $p>0.05)$ difference in the predicted FEV1 between Group A $(60.93 \pm 10.97)$ and Group B (60.39 \pm 10.47$)$ (Fig.1).

There was no significant $(p>0.05)$ difference in in all the PFT parameters between the groups at 0 week. FEV1 was found to be significantly higher in Group B compared to Group $A$ at 12 weeks $(p=0.002)$ and 24 weeks $(p=0.007)$. PEFR was found to be significantly higher in Group B compared to Group A at 12 weeks $(p=0.01)$ and 24 weeks $(p=0.007)$.

FEF was found to be significantly higher in Group $B$ compared to Group A at 12 weeks $(p=0.006)$ and 24 weeks $(p=0.002)$. FEV1/FVC was found to be insignificantly higher in Group B compared to Group $A$ at 12 weeks $(p>0.05)$ and 24 weeks $(p>0.05)$. MVV was found to be significantly higher in Group $B$ compared to Group A at 12 weeks $(p=0.002)$ and 24 weeks $(p=0.002)($ Table-2). 
Table-2: Comparison of PFT between the groups across the time periods.

\begin{tabular}{|c|c|c|c|}
\hline Time periods & Group A $(n=100)$ & Group $B(n=100)$ & p-value1 \\
\hline \multicolumn{4}{|l|}{ FEV1 } \\
\hline 0 week & $1.25 \pm 0.45$ & $1.31 \pm 0.39$ & 0.25 \\
\hline 12 weeks & $1.33 \pm 0.45$ & $1.52 \pm 0.39$ & $0.002 *$ \\
\hline 24 weeks & $1.41 \pm 0.46$ & $1.57 \pm 0.38$ & $0.007^{*}$ \\
\hline \multicolumn{4}{|l|}{ PEFR } \\
\hline 0 week & $3.13 \pm 1.41$ & $3.28 \pm 1.25$ & 0.43 \\
\hline 12 weeks & $3.33 \pm 1.38$ & $3.80 \pm 1.17$ & $0.01 *$ \\
\hline 24 weeks & $3.46 \pm 1.44$ & $3.95 \pm 1.10$ & $0.007 *$ \\
\hline \multicolumn{4}{|l|}{ FEF } \\
\hline 0 week & $0.91 \pm 0.59$ & $1.00 \pm 0.51$ & 0.26 \\
\hline 12 weeks & $0.93 \pm 0.62$ & $1.15 \pm 0.49$ & $0.006 *$ \\
\hline 24 weeks & $1.02 \pm 0.76$ & $1.30 \pm 0.51$ & $0.002 *$ \\
\hline \multicolumn{4}{|l|}{ FEV1/FVC } \\
\hline 0 week & $62.92 \pm 3.37$ & $60.71 \pm 6.93$ & 0.07 \\
\hline 12 weeks & $63.96 \pm 7.22$ & $63.69 \pm 6.89$ & 0.78 \\
\hline 24 weeks & $65.09 \pm 6.68$ & $65.30 \pm 6.91$ & 0.82 \\
\hline \multicolumn{4}{|l|}{ MVV } \\
\hline 0 week & $48.19 \pm 19.60$ & $51.18 \pm 17.01$ & 0.25 \\
\hline 12 weeks & $52.04 \pm 20.56$ & $60.34 \pm 16.06$ & $0.002 *$ \\
\hline 24 weeks & $53.59 \pm 21.03$ & $61.99 \pm 16.12$ & $0.002 *$ \\
\hline
\end{tabular}

1Unpaired t-test, *Significant

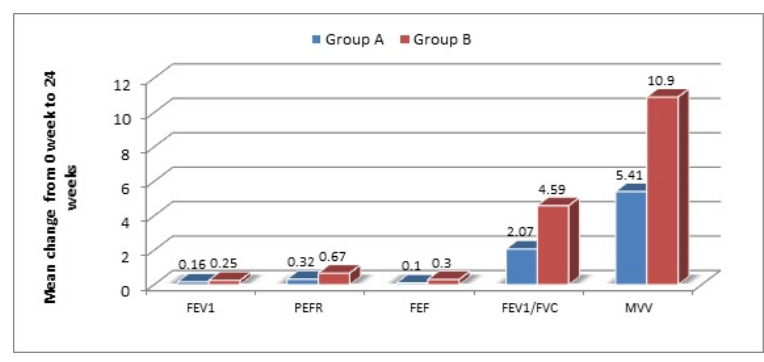

Fig.2: Comparison of mean change in PFT parameters from 0 week to 24 weeks in Group A and Group B

Table-3: Comparison of clinical improvement between the groups

\begin{tabular}{|l|l|l|l|}
\hline Clinical improvement & Group A $(\mathrm{n}=100)$ & Group B $(\mathrm{n}=100)$ & p-value1 \\
\hline
\end{tabular}

\begin{tabular}{|l|l|l|l|l|l|} 
& No. & $\%$ & No. & $\%$ & \\
\hline Improved & 100 & 100.0 & 100 & 100.0 & NA \\
\hline Not improved & 0 & 0.0 & 0 & 0.0 & \\
\hline
\end{tabular}

1 Chi-square test, NA-Not applicable as $100 \%$ in both the groups

There was significant $(p<0.001)$ increase in FEV1 in both the groups from 0 week to 24 weeks. However, mean change in FEV1 was higher in Group B than Group A. There was significant $(p=0.001)$ increase in PEFR in both the groups from 0 week to 24 weeks.
However, mean change in PEFR was higher in Group B than Group A. There was significant $(p<0.05)$ increase in FEF in both the groups from 0 week to 24 weeks. However, mean change in FEF was higher in Group B than Group A. There was significant $(p<0.05)$ increase in FEV1/FVC in both the groups from 0 week to 24 weeks. However, mean change in FEV1/FVC was higher in Group B than Group A. There was significant $(p=0.001)$ increase in MVV in both the groups from 0 week to 24 weeks. However, mean change in MVV was higher in Group B than Group A (Fig.2).

There was clinical improvement among all the patients in both the groups (Table-3).

\section{Discussion}

Patients with moderate-severe stable COPD already have more serious airway limitation, and they need to receive long-term low flow oxygen uptake, eliminating phlegm and relieving asthma as well as other treatment in daily life to discharge the airway secretions and avoid acute onset of infection and COPD aggravation [7].

The present study was conducted in the Department of Pharmacology, Department of Pulmonary Medicine, Hind Institute of Medical Sciences, Safedabad, Barabanki with the objective to compare the effect of 24 weeks treatment with inhaled Glycopyrronium bromide +Salmeterol/Fluticasone and inhaled Tiotropium bromide+ Salmeterol/Fluticasone on airflow obstruction and symptoms, by assessing clinical improvement as well as alteration in pulmonary function tests in cases of moderate to severe COPD. A total of 100 patients were included in each group.

In the present study, there was no significant ( $p>0.05)$ difference in the predicted FEV1 between Group A $(60.93 \pm 10.97)$ and Group B $(60.39 \pm 10.47)$. This finding was in consistent with the study by Peter et al [8] in which predicted FEV1 was $57.36 \pm 13.98$ and $56.86 \pm 13.81$ in Glycopyrronium+SAL/FP and Tiotropium +SAL/FP groups respectively. In the study by Anthony et al in2018 [9], the mean post-bronchodilator FEV1was approximately $55 \%$ predicted, and mean FEV1reversibility was 16.7 and $18.6 \%$ in the glycopyrronium and tiotropium groups, respectively.

Combining inhaler therapies from different classes of drugs for COPD is commonly recommended GOLD, 2014 [10,11,12] and often pursued However, 
It is important to know if there is merit in doing so; in particular if there is comparable efficacy for medications from the same therapeutic class and whether therapy with GLY+LABA/ICS has advantages over therapy with LABA/ICS in patients with moderate to severe disease. The GLISTEN study demonstrates that TIO and GLY are comparable when added to a LABA/ICS combination in moderate to severe COPD patients, but more importantly shows the superiority of using GLY+LABA/ICS over using a LABA/ICS alone. This is the first time this has been effectively demonstrated.

In the present study, there was no significant $(p>0.05)$ difference in FEV1 between the groups at 0 week. FEV1 was found to be significantly higher in Group B compared to Group A at 12 weeks $(p=0.002)$ and 24 weeks $(p=0.007)$. There was significant $(p=0.001)$ increase in FEV1 in both the groups from 0 week to 12 and 24 weeks. However, mean change in FEV1 was higher in Group $B$ than Group A in this study. Peter et al (8) demonstrated the non-inferiority of GLY to TIO when combined with SAL/FP. Comparable outcomes for GLY versus TIO were also demonstrated for all other outcomes' measures: health status, rescue medication use, nocturnal symptoms and activity performance.

The findings of this study in terms of FEV1 are inconsistent with results for GLY versus TIO noninferiority studies in a monotherapy setting, as demonstrated in both open-label and blinded randomized controlled trials. Although not measured in the current study, GLY has been shown in other studies to be superior to TIO in terms of time to onset and on peak FEV1 results $[13,14]$.

Peter et al [8] also found that GLY in combination with SAL/FP demonstrated statistically and clinically significant improvements in lung function compared to PLA+ SAL/FP at 4,8 and 12 weeks. In addition, over 12 weeks GLY+SAL/FP provided statistically significant improvements in health status, symptom relief and rescue medication in comparison to SAL/FP alone. Furthermore, there was no increase in AEs when GLY was used with SAL/FP and specifically there was no increase in cardiovascular events or any other SAEs. This adds to existing clinical trial data concerning GLY safety and tolerability $[15,16]$.

There have been many studies comparing LABA/ICS therapy with individual monotherapies (ICS, LABA, LAMA).
A systematic review by Kew et al [16] of 71 randomized controlled trials $(n=73 \quad 062 ;>6$ months' duration) comparing LABA, LAMA, ICS or combined LABA/ICS and PLA, showed health status and lung function were improved most if taking LABA/ICS. The review also concluded that LAMAs and LABAs had similar efficacy although triple therapies were not included in their analysis.

Improving daily symptoms, health status and lung function are important goals in COPD therapy, while reducing exacerbations is equally important. These outcomes may be independent or interactive. The data from studies addressing triple therapy, show less obvious impact on exacerbations and more on health status and lung function. A study of Magnussen et al, in 2014[17] suggests that removing ICS does little to change exacerbation rates but is associated with an incremental reduction in FEV1, suggesting a complex interplay between drug therapy and clinical outcomes that needs more careful evaluation.

In the present study, there was no significant ( $p>0.05)$ difference in FEF between the groups at 0 week. FEF was found to be significantly higher in Group B compared to Group A at 12 weeks $(p=0.006)$ and 24 weeks $(p=0.002)$. Xiang [18] analyzed the effect of tiotropium bromide combined with salmeterol fluticasone inhalation on airway function and airway inflammation in patients with moderate-severe stable COPD and found that after 2 weeks of treatment, small airway function parameters FEF25, FEF25-75 and FEF75 levels of observation group were significantly higher than those of control group.

Wang et al [19] compared the efficacy and safety of tiotropium bromide inhalation powder (Spiriva) and doxofylline oral tablet (doxofylline) in the treatment of chronic obstructive pulmonary disease and found that FEV1/FVC\% was significantly higher than those before the medication. In the present study, there was no significant $(p>0.05)$ difference in FEV1/FVC between the groups at 0 week. FEV1/FVC was found to be insignificantly higher in Group $B$ compared to Group $A$ at 12 weeks $(p>0.05)$ and 24 weeks $(p>0.05)$. Also, there was significant $(p<0.05)$ increase in FEV1/FVC in both the groups from 0 week to 24 weeks. However, mean change in FEV1/FVC was higher in Group B than in Group A.

In the present study, there was no significant ( $p>0.05$ ) difference in PEFR between the groups at 0 week. 
PEFR was found to be significantly higher in Group B compared to Group $A$ at 12 weeks $(p=0.01)$ and 24 weeks $(p=0.007)$. It was also observed that there was significant $(p=0.001)$ increase in PEFR in both the groups from 0 week to 24 weeks. However, mean change in PEFR was higher in Group B than Group A.

This study found that there was no significant $(p>0.05)$ difference in MVV between the groups at 0 week. MVV was found to be significantly higher in Group B compared to Group A at 12 weeks $(p=0.002)$ and 24 weeks $(p=0.002)$. Also, there was significant $(p=0.001)$ increase in MVV in both the groups from 0 week to 24 weeks. However, mean change in MVV was higher in Group B than Group A. In the best knowledge of researcher, there is no study reporting the comparison of PEFR and MVV in using both the drugs, hence, comparison could not be done.

Mariana et al [20] reported that patients who received tiotropium bromide, had better clinical and laboratory dynamics and a full recovery of surfaceactive fraction of the pulmonary surfactant system, which clearly correlates with the prolongation of treatment.

\section{Conclusion}

Glycopyrronium is a once-daily, inhaled long-acting muscarinic antagonist demonstrating similar efficacy to inhaled tiotropium in patients with moderate-tosevere COPD; however, the benefit of LAMAs on COPD symptoms has been variable. In present study once-daily glycopyrronium demonstrated efficacy similar to tiotropium when combinedwith $\mathrm{SAL} / \mathrm{FP}$ in patients with moderate and severe COPD.

Since COPD is a progressive disease in which many patients develop an acute or sustained deterioration and data on the prevention of clinically important deteriorations using long acting muscarinic antagonists are limited, it is recommended that larger studies may be undertaken to include such criteria. The present study focusses on efficacy of the two drugs used in combinations in improvement as end point. Another important recommendation is duration of study as COPD is chronic disease and assessment of efficacy after long term use will be more relevant.

\section{Contribution by authors}

1. Dr. Deepak Kumar is post-graduate student in
Pharmacology and has submitted this work in part fulfilment of MD degree in Pharmacology at RML Awadh University, Faizabad. All practical work has been done by him. Dr. Ram Babu Raman worked as a colleague and worked with patients when first author was not available for any reason.

2. Dr. Rahul Srivastava has helped in recruitment and exclusion of patients and also responsible for planning the study and timetable. He was responsible for evaluation of patients.

3. Dr. A K Khare Corresponding author, supervised the study and prepared the manuscript and corrections. He was also responsible for institutional approval to undertake study.

4. Dr. Dibyadeb Ghosh, Professor and the Head of Pharmacology department was responsible for verification of records and statistics.

\section{Reference}

01. Decramer M, Janssens W, Miravitlles M. Chronic obstructive pulmonary disease. Lancet. 2012 Apr 7;379(9823)1341-51.

doi: 10.1016/S0140-6736(11)60968-9 [Crossref]

02. Hogg JC, McDonough JE, Suzuki M. Small airway obstruction in COPD- new insights based on micro-CT imaging and MRI imaging. Chest. 2013 May; 143(5)1436-1443.

doi: $10.1378 /$ chest.12-1766 [Crossref]

03. Pavkov R, Mueller $S$, Fiebich $K$, et al. Characteristics of a capsule based dry powder inhaler for the delivery of indacaterol. Curr Med Res Opin. 2010 Nov;26(11)2527-33.

doi: 10.1185/03007995.2010. 518916. Epub 2010 Sep 15 [Crossref]

04. Sykes DA, Dowling MR, Leighton-Davies J, et al. The Influence of receptor kinetics on the onset and duration of action and the therapeutic index of NVA237 and tiotropium. J Pharmacol Exp Ther. 2012 Nov;343(2)520-8. doi: $10.1124 /$ jpet.112.194456 [Crossref]

05. Bourbeau J, Christodoulopoulos P, Maltais F, et al. Effect of salmeterol/fluticasone propionate on airway inflammation in COPD- a randomised controlled trial. Thorax. 2007 Nov;62(11)93843.

[Crossref] 
06. Johnson M. Corticosteroids- potential beta2agonist and anticholinergic interactions in chronic obstructive pulmonary disease. Proc Am Thorac Soc. 2005;2(4)320-5; discussion 340-1. [Crossref]

07. Li Y, Li YH, Luo YW, et al. Effects of inhaled short-acting bronchodilators on diaphragm function and neural respiratory drive during maximal isocapnic ventilation in patients with chronic obstructive pulmonary disease. Nan Fang Yi Ke Da XueXue Bao. 2016 Feb;36(2)2327.

[Crossref]

08. Peter A Frith, Philip J Thompson, Rajeev Ratnavadivel, Catherina L Chang, Peter Bremner, Peter Day, Christina Frenzel, Nicol Kurstjens, the Glisten Study Group. Glycopyrronium once-daily significantly improves lung function and health status when combined with salmeterol/fluticasone in patients with COPD- the GLISTEN study-a randomized controlled trial. Thorax. 2015;70;519-527. [Crossref]

09. D'Urzo A, Bader G, Shen S, et al. Comparison of glycopyrronium versus tiotropium on the time to clinically important deteriorations in patients with COPD- a post-hoc analysis of randomized trials. NPJ Prim Care Respir Med. 2018 May $24 ; 28(1) 18$.

doi: 10. 1038/s41533-018-0084-8 [Crossref]

10. The Global Strategy for the Diagnosis. Management and Prevention of COPD, Global Initiative for Chronic Obstructive Lung Disease. GOLD. 2014.

[Crossref]

11. Bourbeau J, Sebaldt RJ, Day A, et al. Practice patterns in the management of chronic obstructive pulmonary disease in primary practice- the CAGE study. Can Respir J. 2008 Jan-Feb;15(1)13-9.

DOI: $10.1155 / 2008 / 173904$ [Crossref]

12. White $P$, Thornton $H$, Pinnock $H$, et al. Overtreatment of COPD with inhaled corticosteroids--implications for safety and costs- cross-sectional observational study. PLoS One. 2013 Oct 23;8(10)e75221.

doi: 10.1371/journal.pone.0075221 [Crossref]
13. Chapman KR, Beeh KM, Beier J, et al. A blinded evaluation of the efficacy and safety of glycopyrronium, a once-daily long-acting muscarinic antagonist, versus tiotropium, in patients with COPD- the GLOW5 study. BMC Pulm Med. 2014 Jan 17;14;4.

doi: $10.1186 / 1471-2466-14-4$ [Crossref]

14. Kerwin E, Hébert J, Gallagher N, et al. Efficacy and safety of NVA237 versus placebo and tiotropium in patients with COPD- the GLOW2 study. Eur Respir J. 2012 Nov;40(5)1106-14.

doi: $10.1183 / 09031936.00040712$ [Crossref]

15. Beeh KM, Singh D, Di Scala L, et al. Once-daily NVA237 improves exercise tolerance from the first dose in patients with COPD- the GLOW3 trial. Int $]$ Chron Obstruct Pulmon Dis. 2012;7;503-13.

doi: $10.2147 /$ COPD.S32451 [Crossref]

16. Kew KM, Dias S, Cates CJ. Long-acting inhaled therapy (beta-agonists, anticholinergics and steroids) for COPD- a network meta-analysis. Cochrane Database Syst Rev. 2014 Mar 26; (3)CD010844.

doi: 10.1002/14651858.CD010844.pub2 [Crossref]

17. Magnussen $H$, Watz $H$, Kirsten $A$, et al. Stepwise withdrawal of inhaled corticosteroids in COPD patients receiving dual bronchodilationWISDOM study design and rationale. Respir Med. 2014 Apr;108(4)593-9.

doi: $\quad 10.1016 /$ j.rmed.2014.01.002 [Crossref]

18. Xiang Min. Effect of tiotropium bromide combined with salmeterol fluticasone inhalation on airway function and airway inflammation in patients with moderate-severe stable COPD. Journal of Hainan Medical University. 2016;22(23)24-27.

[Crossref]

19. Wang T, Luo G, Hu Y, et al. Comparative study on the efficacy of tiotropium bromide inhalation and oral doxofylline treatment of moderate to severe stable chronic obstructive pulmonary disease. J Huazhong Univ Sci Technolog Med Sci. 2011 Oct;31(5)614.

doi: 10.1007/s11596-011-0570-5 [Crossref] 
20. Oleksandr Varunkiv, Iryna Savelikhina. Tiotropium bromid- Efficacy and safety in complex treatment of COPD. European Respiratory Journal. 2017; 50.

[Crossref] 